\section{УДК: 617.542-053.01-074-036:616-053.31}

\section{И.Н.Сафонова, И.С. Лукьянова *}

Харьковская медицинская академия последипломного образования, кафедра ультразвуковой диагностики

(г. Харьков, Украина),

ГУ «Институт педиатрии акушерства

и гинекологии НАМН Украины»*

(г. Киев, Украина)

\section{ПРОГНОЗИРОВАНИЕ ПОСТНАТАЛЬНЫХ РЕЗУЛЬТАТОВ ПРИ РАЗЛИЧНЫХ ЭХОГРАФИЧЕСКИХ ВАРИАНТАХ НЕКАРДИАЛЬНЫХ АНОМАЛИЙ ГРУДНОЙ ПОЛОСТИ ПЛОДА}

Ключевые слова: антенатальная эхографическая диагностика, легкие плода, постнатальньй исход.

\begin{abstract}
Резюме. Антенатальная диагностика гипоплазии легких u прогнозирование перинатального риска и постнатального результата на основании анализа эхографической картины органов грудной клетки плода имеет важное значение в акушерской клинике и в пренатальном консультировании. Проведен анализ эхограмм и постнатальных результатов 24 плодов, у которых после 22 гестационных недель была обнаружена аномальная эхографическая картина грудной клетки. На основании литературного обзора и собственных наблюдений разработаны критерии перинатального прогноза и необходимости постнатального катамнестического мониторинга в зависимости от эхографической картины грудной клетки плода. Учитывая лимитированные возможности ретроспективного одноцентрового исследования, можно считать необходимыми дальнейшие проспективные многоцентровые исследования, определяюшие антенатальные эхографические изменения легких плода и их ассоциацию с перинатальным результатом.
\end{abstract}

Прогнозирование перинатального риска и постнатального результата на основании анализа эхографической картины органов грудной клетки плода имеет важное значение в акушерской клинике и в пренатальном консультировании беременной. С другой стороны, в связи с тем, что у плода легкие не функционируют и находятся в спавшемся состоянии, на современном этапе эхография не способна предсказать функциональную полноценность дыхательной системы после рождения [1].

Аномалиям легких, которые наиболее часто диагностируются на антенатальном этапе, являются кистозно-аденоматозный порок легкого (КАПЛ) и легочной секвестр (ЛС) - нормальная ткань легких, имеющая аномальное кровоснабжение из аорты, а не из легочных сосудов [2]. Их дифференциальный диагноз проводится с применением цветового допплеровского картирования (ЦДК) и определением питающей артерии измененного легкого: кровоснабжение КАПЛ осуществляется из легочных артерий, в отличие от секвестра, питающегося ветвью аорты $[3,4]$. Постнатальный прогноз при этих аномалиях не связан с высоким перинатальным риском, спонтанный регресс КАПЛ возможен внутриутробно (до 75\% случаев) либо после рождения ребенка [4]. Даже выраженные изменения, при отсутствии водянки, могут регрессировать с благоприятным прогнозом выживаемости детей до 100\% [5].

Гипоплазия легких (ГЛ) - порок развития, клинически ассоциированный как с перинатальными и младенческими потерями, так и с заболеваниями, манифестирующими в более поздние периоды жизни. Не только антенатальная ультразвуковая диагностика (УЗД), но также и рентгенологическое обследование новорожденного не позволяет абсолютно точно диагностировать ГЛ [6], а патоморфологический диагноз ГЛ устанавливается на основании отношения массы легочной ткани к массе тела новорожденного. При раннем (во II триместре) преждевременном развыве плодного пузыря или других причинах длительного маловодия вероятность ГЛ велика, однако антенатальная УЗД летальной ГЛ является неоднозначной и непростой задачей, несмотря на возможности прямой визуализации легких плода в различных проекциях. Среди многочисленных методик измерений легких наиболее адекватно судить о развитии грудной клетки и легких позво- 
ляет отношение окружности грудной клетки (ОГК) к окружности живота (ОЖ) плода, которое в норме во II-III триместрах составляет 0,8 [7]. Однако, результаты мета-анализа, опубликованного в 2012 году, показали ограниченное значение этого параметра в предсказании летальной ГЛ [8]. Высокую позитивную предиктивную ценность, по другим данным, имеет оценка кардио-торакального отношения (КТО) [3]. На аксиальном сечении грудной клетки плода КТО норме составляет 0,3. Наиболее тяжелым клиническим вариантом снижения КТО является последовательность изменений при обструкции верхних дыхательных путей плода, проявляющаяся увеличением размера легких [9]. Возрастание КТО может наблюдаться как при кардиомегалии без ГЛ, так и при нормальных размерах сердца и ГЛ.

Изменения эхографической картины грудной клетки плода наблюдаются также при врожденной диафрагмальной грыже (ВДГ). Выживаемость при синдромальной диафрагмальной грыже крайне низкая - менее $15 \%$, а уровень неонатальной смертности при антенатальной детекции изолированной ВДГ, по данным статистики европейских перинатальных центров, за последнее десятилетие составляет около $30 \%$ [4]. Плохим прогностическим признаком при изолированной правосторонней ВДГ является наличие в грудной полости части печени (признак liver-up), особенно в случаях, когда более половины печени эктопировано в грудную полость (признак liver up более 50\%) [4]. Кроме того, в последние годы много публикаций посвящались прогнозированию перинатального исхода при ВДГ путем вычисления LHR (lung-head ratio) - отношения между размерами легких и окружностью головы. При этом благоприятный постнатальный прогноз у плода отмечался при LHR>2, неблагоприятный - при LHR $<1,0-1,5$, а показатель LHR $<0,6$ - абсолютно несовместим с жизнью $[1,4,8]$.

Наличие жидкости в плевральных полостях является аномалией [10]. Наименее тяжелые последствия имеет умеренно выраженный транзиторный гидроторакс, а также хилоторакс, развивающийся при аномалиях грудных лимфатических сосудов. Существует мнение, что клиническое течение гидроторакса непредсказуемо, а наиболее частыми причинами неонатальных потерь при антенатальном гидротораксе являются респираторные инфекционно-воспалительные заболевания на фоне ГЛ [10]. По некоторым данным, смертность при двустороннем гидротораксе плода достигает 97\% в связи с ГЛ [4]. В то же время, в случаях антенатального билатерального гидроторакса, эхографически нельзя судить о наличии гипоплазии и ателектаза легких, так как легкие могут восстанавливаться и функционировать после эвакуации жидкости или спонтанного регресса гидроторакса [3].

В связи с вышеизложенным, целью исследования был анализ перинатальных результатов при различных эхографических вариантах некардиальных аномалий грудной полости плода, который в дальнейшем можно использовать для прогноза в раннем неонатальном периоде и разработки рекомендаций по акушерской тактике.

\section{Материалы и методы}

Проведен расширенный анализ эхографических изображений и перинатальных результатов 24 случаев, в которых после 22 гестационных недель обнаруживалась аномальная УЗ картина грудной клетки плода: снижение ОГК/ОЖ - 4 случая, изменение КТО - 12 случаев, наличие плеврального выпота - 4 случая, наличие в грудной полости эктопированого желудка - 3 случая и бронхогенной кисты - 1 случай. В группу для анализа не включались случаи кардиальных аномалий, полисерозита, а также синдромальные варианты диафрагмальной грыжи плода, поскольку перинатальные результаты при таких аномалиях имеют мультифакторную зависимость, а клиническое прогнозирование не может основываться исключительно на эхографической картине легких. Ультразвуковые исследования проводились на аппаратах Voluson 730 pro (GE, США) и Philips HD 11 (Нидерланды).

Соотношение ОГК/ОЖ и КТО плода оценивались аппаратным автоматическим способом путем трассировки соответствующих окружностей и определения значений их площадей и длин. При ВДГ оценивалось соотношение LHR c измерением легкого, контрлатерального по отношению к позиции грыжи, на уровне 4-камерного сечения сердца, окружность головы измерялась на уровне трансталамической аксиальной плоскости. Площадь легкого вычислялась аппаратным способом после ручной трассировки контура легкого. Проанализированы исходы беременности всех пациенток, обследованных эхографически на антенатальном этапе. В 
случаях перинатальных либо младенческих потерь во всех случаях изучались результаты пато-морфологического исследования.

\section{Результаты и обсуждение}

Во всех 24 изученных случаях описанные эхографические особенности были обнаружены во второй половине беременности - в конце II и в III триместре. Перинатальные и младенческие потери в исходе беременности имели место у 15 из 24 (62,5\%) женщин: антенатальная - 2, ранняя неонатальная - 6, поздняя неонатальная - 3, младенческая - 4 . Безусловно, перинатальная смертность в этой серии случаев имела мультифакторный генез: недоношенность (6 случаев), комбинации патологии грудной клетки с другими аномалиями (6 случаев), тяжелая плацентарная дисфункция, осложненная дистрессом (4 случая). Патоморфологически ГЛ была диагностирована в 3 случаях, ателектаз - в 2 случаях.

Эхограммы на рис. 1 иллюстрируют эхографические особенности грудной клетки плода при изменении КТО, их клинические характеристики и исходы. Из 22 родившихся новорожденных 19 перенесли РДС, 18 - проводилась интубационная ИВЛ, 2 - неинвазивная респираторная поддержка, у 4 имелось самостоятельное дыхание (диаграмма на рис. 2). У 5 из 9 выживших детей постнатально развивались пневмония (2 случая) и бронхо-легочная дистплазия (БЛД) (3 случая). Спонтанный регресс заболевания имел место в 2 случаях при одностороннем гидроторакce, наиболее вероятной причиной которого являлся первичный хилоторакс.

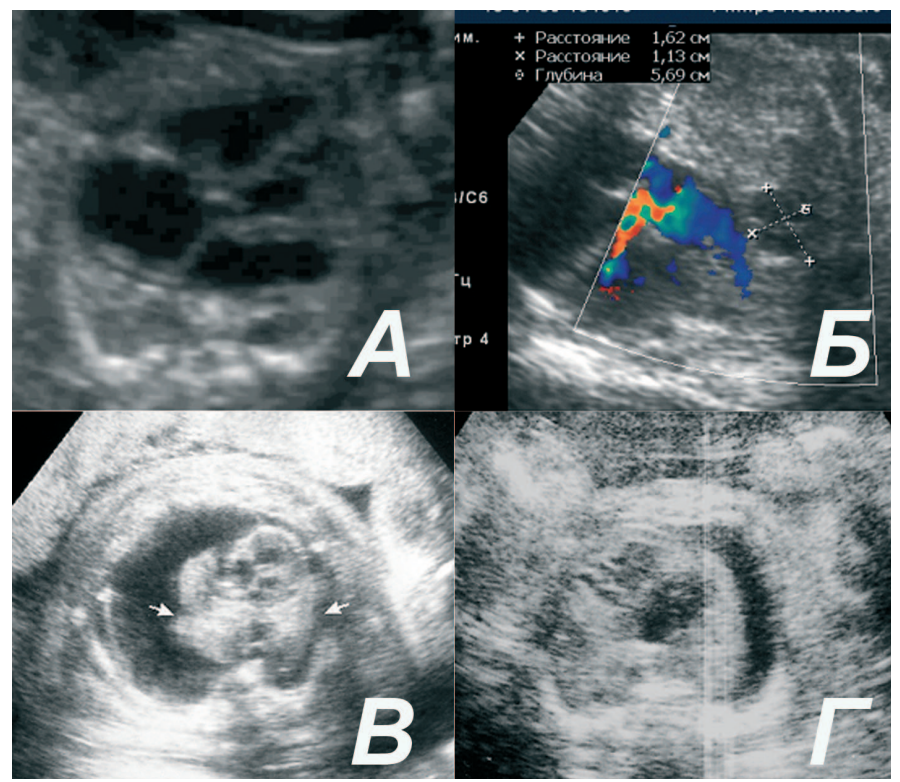

Рис. 1. Эхографические особенности грудной клетки плода при измененном КТО

При анализе клинического течения и постнатальных исходов случаев, представленных на рис. 1, выявлено, что:

- Рис.1.А: при КТО 0,71 имел место антенатальный дистресс плода, постнатально - РДС, ИВЛ, синдром полиорганной недостаточности, неонатальная смерть; патоморфологический диагноз - врожденная гипоплазия и ателектаз левого легкого на фоне перенесенного нарушения плацентарно-плодового кровообращения;

- Рис. 1.Б: при наличии кистозной полости размерами 16х11 мм в структуре левого легкого плода отмечалось бессимптомное течение в неонатальном периоде, постнатально - бронхогенная киста с дальнейшей хирургической коррекцией;
- Рис. 1.В: при КТО 0,2 с наличием билатерального гидроторакса, постнатально развился РДС, ранняя неонатальная смерть, патоморфологический диагноз - трахеоларингеальная атрезия;

- Рис. 1.Г: при КТО 0,29 с наличием выпота в правой плевральной полости (первичный хилоторакс), в неонатальном периоде - бессимптомное течение и регресс.

Постнатальные результаты при эхографических аномалиях грудной клетки у плода приведены на рис.2.

Анализ пренатальных эхографических изображений при сопоставлении с данными пре- и постнатального катамнеза, показал, что в 3 случаях при истинной ГЛ при прямой визуализации легких отсутствовали 
значимые эхографические изменения: при непосредственном измерении размеры легких не выходили за гестационные пределы 10-го процентиля, а их эхо-структура (эхогенность, звукопроводимость) не имела характерных особенностей и отличий (рис. 3А). Эхографическое изображение легких плода при их прямой визуализации, также как

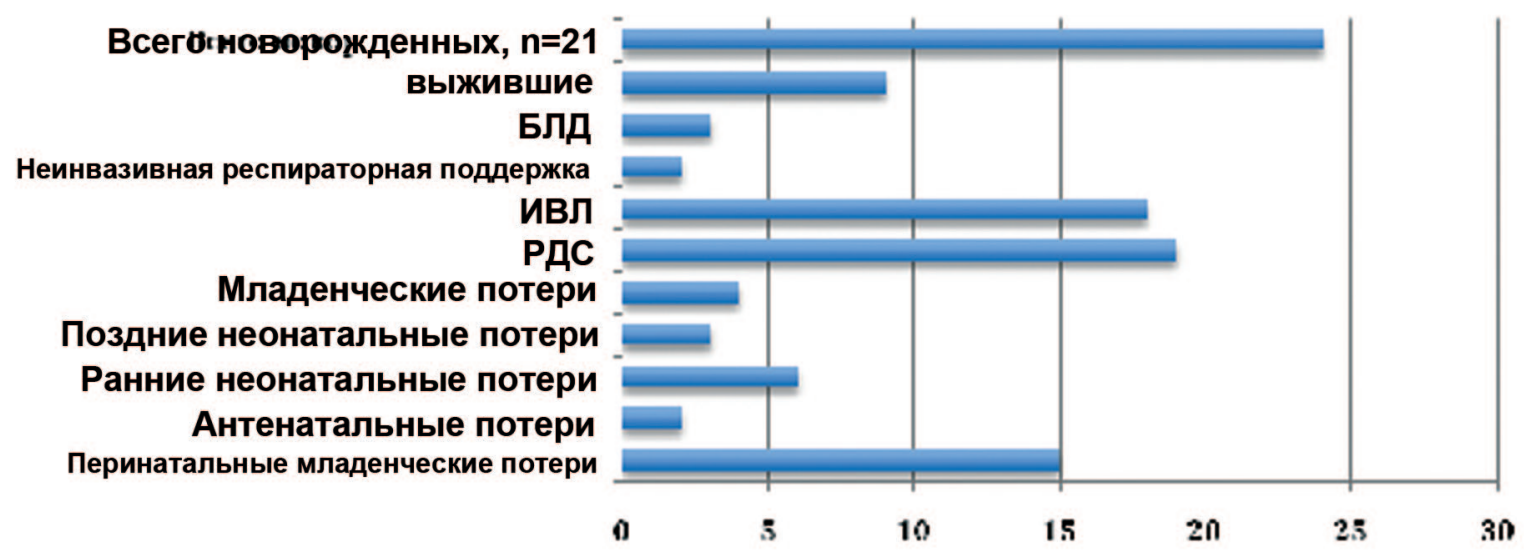

Рис. 2. Заболеваемость и смертность в раннем неонатальном периоде при эхографических аномалиях органов грудной клетки, выявленных пренатально $(n=24)$

и оценка КТО, не позволяли диагностировать ГЛ, прогнозировать дыхательную функцию и тип дыхательных расстройств после рождения (рис. 3Б).

На рис 3.А представлена эхограмма плода в сроке 36 недель (гипоплазия грудной клетки (ОГК/ОЖ 0,68), КТО=0,36, эхо-структура и размер легких без особенностей) на фоне длительного агидрамниона, беременность закончилась неонатальной смертью (ПМД - гипоплазия легких); рис. 3.Б - двуплодная беременность 27-28 недель, несмотря на различную эхографическую картину грудной клетки и легких двух близнецов с выраженным различием КТО (0,30 и 0,72), оба плода имели одинаковый тип респираторных нарушений после рождения, а ГЛ либо их ателектаз в обоих случаях отсутствовали.

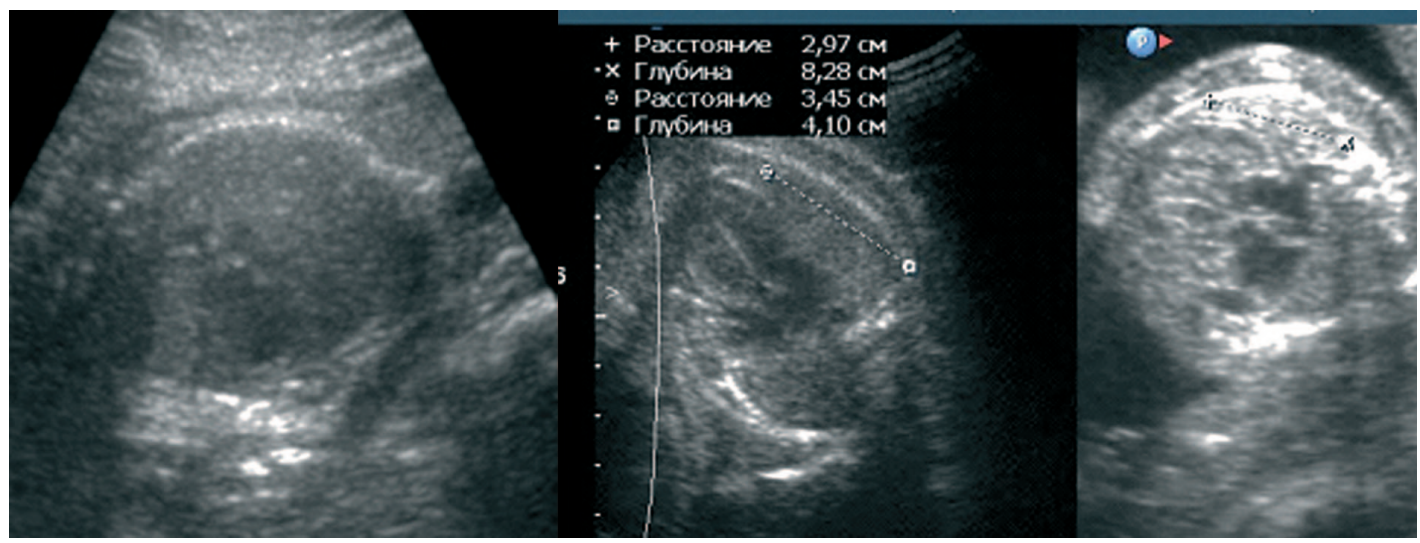

Рис. 3. Прямая визуализация легких у плодов с ГЛ (А) и без ГЛ (Б)

Однако неблагоприятным (тяжелые полиорганные неонатальные нарушения, младенческая смерть) был постнатальный исход близнеца с измененным КТО (эхограмма справа).

Увеличенное КТО также не имело прямой корреляционной связи с ГЛ и ателектазом легких, диагностированными патоморфологически постмортально (рис. 4).

Однако, представляется важным тот факт, что 10 из 12 плодов с неблагоприятным постнатальным результатом имели все же преимущественно аномальные значения КТО (рис. 5). Как видно из данного рисунка, неблагоприятные постнатальные результаты (верхний ряд) в большинстве случаев ассоциировались с аномальным значением КТО (горизонтальная ось - значения КТО).

Оценка отношения ОГК/ОЖ также не во всех случаях позволяла точно диагностировать ГЛ, хотя в 3 случаях из 4 снижение этого отношения соответствовало патоморфологическому диагнозу ГЛ. Однако, весьма низкая 


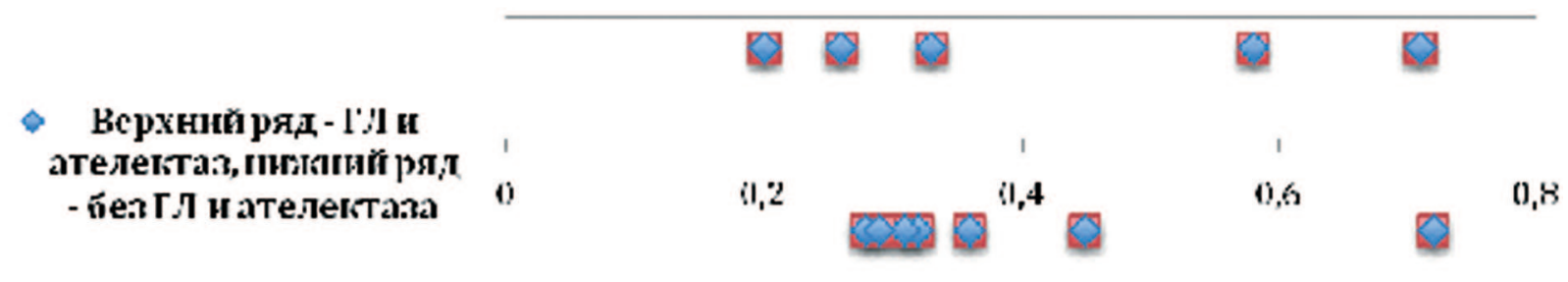

Рис. 4. Взаимосвязь между значением КТО (по данным антенатальной эхографии) и наличием ГЛ либо ателектаза легких (по данным патоморфологического исследования)

популяционная частота гипоплазии грудной клетки плода и, соответственно, небольшое количество исследований в серии, не позволяют достоверно судить об операционных характеристиках метода оценки отношения ОГК/ОЖ.
Анализ эхографических изображений грудной клетки при несиндромальной ВДГ давал возможность диагностики ГЛ и прогнозирования тяжелых расстройств дыхательной функции после рождения у 2 из 3 плодов. При

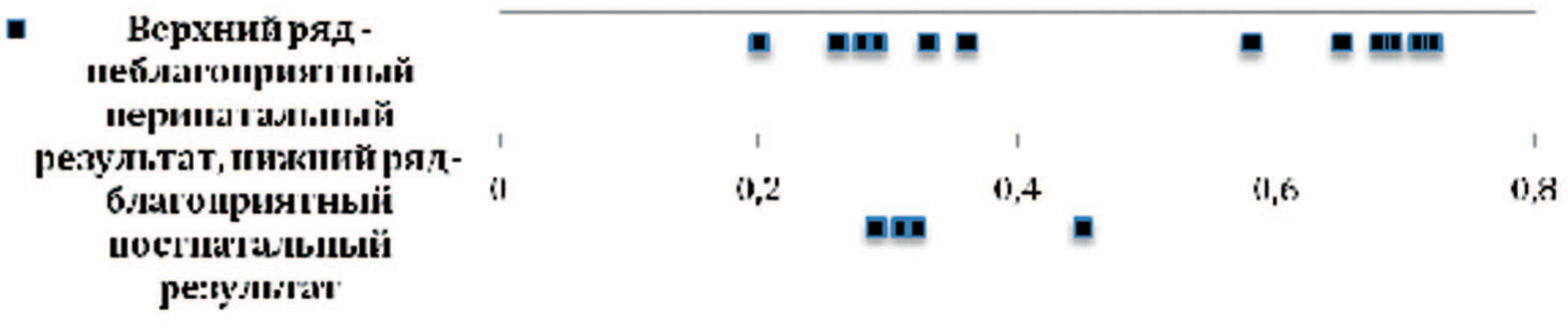

Рис. 5. Взаимосвязь между значением КТО (по данным антенатальной эхографии) и постнатальными результатами

прямой визуализации органов грудной клетки в одном из случаев отмечалось наличие выраженного правостороннего гидроторакса, декстрапозиции средостения, признака liverup, подозревалась гипоплазия правого легкого, которая была впоследствии подтверждена. Оценка площади контрлатерального легкого и соотношения LHR позволяла судить о различном прогнозе дыхательной функции после рождения (рис. 6.А, 6.Б). На основании оценки LHR у двух плодов с несиндромальной ВДГ при $\mathrm{LHR}=0,35$ и 0,55 была верно диагностирована летальная ГЛ и прогнозированы критические нарушения дыхательной функции после рождения, тогда как при $\mathrm{LHR}=1,51$ постнатальный послеоперационный результат был позитивным.

У 2 из 4 исследованных плодов с изолированным гидротораксом благоприятными были перинатальные результаты при одностороннем характере поражения. Билатеральный гидроторакс (рис. 1В) в одном из случаев сопровождал трахеоларингеальную атрезию, во втором - вызвал компрессионный ателектаз легких и сопро- вождался неонатальной гибелью. У плода с обнаруженной в 37 недель кистозной полостью размерами 16х11 мм в структуре левого легкого течение неонатального периода было бессимптомным, бронхогенная киста, подтвержденная постнатально, в дальнейшем требовала хирургической коррекции.

В проанализированной серии случаев уровень перинатальной и младенческой смертности составил $62,5 \%$. Частота постнатальной заболеваемости дыхательной системы (РДС, пневмония, БЛД) составила 64\%. Диагностические возможности антенатальной эхографии, как прямой визуализации и измерений легких, так и оценки КТО в диагностике ГЛ и прогнозировании типа респираторных нарушений после рождения в нашей серии были невысокими: чувствительность - 66\%, специфичность - 62\%, точность - 64\%. Однако, у 10 из 12 плодов с аномальным значением КТО имелись в катамнезе неблагоприятные постнатальные результаты.

На основании оценки LHR и наличия признака liver-up более 50\% при $\mathrm{LHR}=0,35$ y двух плодов с несиндромальной ВДГ 


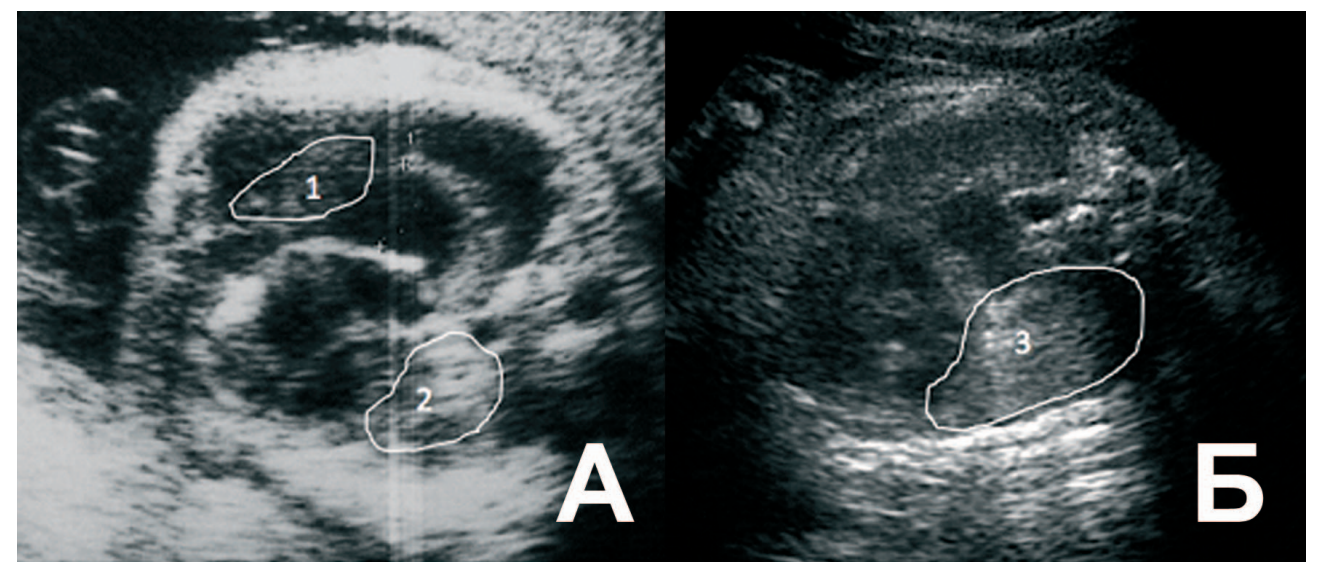

Рис. 6. А) Беременность 29 недель, правосторонняя ВДГ, синистрапозиция средостения, эктопированные желудок и часть печени (признак liver-up, 1) в грудной полости плода, правосторонний гидроторакс, компрессионный ателектаз правого легкого, площадь левого легкого (2) 89 мм3 при HC 250 (LHR=0,35) ( ранняя неонатальная смерть, ГЛ).

Б) Беременность 35 недель, левосторонняя ВДГ, декстрапозиция средостения, эктопированный желудок в грудной полости плода, площадь правого легкого (3) 448 мм3 при НС 304 мм $(\mathrm{LHR}=1,51)$ (постнатально - самостоятельное дыхание, хирургическая коррекция, выздоровление).

была верно диагностирована летальная ГЛ и прогнозированы критические нарушения дыхательной функции после рождения, тогда как при $\mathrm{LHR}=1,51$ постнатальный и послеоперационный результаты были позитивными.

Из 4 исследованных случаев гидроторакca благоприятными были постнатальные результаты 2 плодов, при наличии одностороннего изолированного поражения, a билатеральный гидроторакс сопровождал трахеоларингеальную атрезию, а также компрессионный ателектаз легких.

\section{Выводы}

Эхографическими аномалиями и их комбинациями, ассоциированными с неблагоприятным перинатальным результатом (неонатальная или младенческая смертность, тяжелая неонатальная заболеваемость) можно считать:

- увеличенные эхогенные легкие со сниженным КТО при верхней обструкции респираторного тракта;
- синдромальная ВДГ;

- изолированная ВДГ при LHR<0,6;

- длительный агидрамнион при снижении отношения ОГК/ОЖ;

- правосторнняя диафрагмальная грыжа с наличием признака liver up более 50\%.

Эхографические аномалии и их комбинации, ассоциированные с благоприятным перинатальным результатом:

- КАПЛ;

- секвестр легких;

- монолатеральный гидроторакс;

- изолированная ВДГ при LHR >1,5.

Эхографические аномалии и их комбинации с неопределенным перинатальным прогнозом:

- билатеральный гидроторакс;

- правосторнняя ВДГ с наличием признака liver up менее 50;

- изолированная ВДГ при $0,6<\mathrm{LHR}<1,5$.

Эхографическими аномалиями и их комбинациями, которые требуют постнатального мониторинга, являются бронхогенные кисты легких и монолатератльный гидроторакс.

\section{Литература}

1. Новые ультразвуковые технологии в оценке постнатального прогноза при диафрагмальной грыже у плода / Е.В.Юдина, А.Ю.Разумовский, О.Г.Мокрушина [и др.] // SonoAce Ultrasound. - 2013.- № 24. - С. 12-20.

2. Медведев М.В. Пренатальная эхография: дифференциальный диагноз и прогноз / Медведев М.В. М.: Реальное время, 2009. - 480 с.

3. Callen P.W. Ultrasonography in Obstetrics and Gynecology / Callen P.W. - Elsevier Health Sciences, 2011. $-1180 \mathrm{p}$.

4. Gembruch U. Ultraschalldiagnostik in Geburtshilfe und Gynäkologie (German Edition) / U. Gembruch, K. Hecher, H.Steine. - Springer, 2013.- 460 p.

5. Merz E. Ultrasound in obstetris and gynecology / Merz E. - Thieme, 2005. - 278 p.

6. Колесников Э.М. Пороки развития легких у детей (патогенез, клиника, диагностика, лечение): 
учеб.-метод. пособ. / Колесников Э.М. - Минск.: БелМАПО, 2010. - 79 с.

7. Three- and four-dimensional ultrasound: new methods for evaluating fetal thoracic anomalies / R.Achiron, L.Gindes, Y.Zalei [et al.] // Ultrasound Obstetr. Gynecol. - 2008. - 32(1). - P. 36-43.

8. Accuracy of imaging parameters in the prediction of lethal pulmonary hypoplasia secondary to midtrimester prelabor rupture of fetal membranes: a systematic review and meta-analysis / A.S.P. Teeffelen, J.Van Der Heijden, S.G. Oei [et al.] // Ultrasound Obstetr. Gynecol. - 2012. - 39(5). - P. 495-499.

9. Congenital tracheal atresia in newborn: case report and review of the literature / M. Lupi, LR. Bonetti, N. Trani [et al.] // Patologica. - 2009. - 101(6). - P. 235-9.

10. Higueras T. Fetal pleural effusion / R.Castagno, E.Carreras, N.Toran [et al.] // Donald school journal of Ultrasound Obstet. Gynecol. - 2007. - 1(1). - P. 28-39.

\section{ПРОГНОЗУВАННЯ ПОСТНАТАЛЬНИХ РЕЗУЛЬТАТІВ ПРИ РІЗНИХ ЕХОГРАФІЧНИХ ВАРІАНТАХ НЕКАРДІАЛЬНИХ АНОМАЛІЙ ГРУДНОЇ ПОРОЖНИНИ ПЛОДА}

\author{
І.М. Сафонова, І.С. Лук'янова *
}

Харківська медична академія післядипломної освіти, кафедра ультразвукової діагностики

(м. Харків, Україна)

ДУ «Інститут педіатрії, акушерства

і гінекології НАМН України»

(м. Київ, Україна)

Резюме. Антенатальна діагностика гіпоплазії легень та прогнозування перинатального ризику й постнатального результату на підставі аналізу ехографічної картини органів грудної порожнини плода має важливе значення в акушерській клініці та в пренатальному консультуванні. Проведений аналіз ехограм та перинатальних результатів 24 плодів, у яких після 22 гестаційних тижнів виявлялась аномальна эхографічна картина грудної клітки. На підставі літературного огляду та власних спостережень розроблені критерії перинатального прогнозу і постнатального катамнестичного моніторингу в залежності від ехографічної картини органів грудної порожнини плода. Враховуючи лімітовані можливості ретроспективного одноцентрового дослідження, можна вважати необхідними подальші проспективні багатоцентрові дослідження, що визначають антенатальні ехографічні зміни легень плода та їх асоціацію 3 перинатальним результатом.

Ключові слова: антенатальна эхографічна діагностика, легені плода, постнатальні наслідки

\section{POSTNATAL OUTCOMES PREDICTING IN DIFFERENT SONOGRAPHIC TYPES OF NON-CARDIAC FETAL CHEST ANOMALIES}

\author{
I. Safonva, I. Lukjanova
}

\author{
Kharkiv Medical Academy of Postgraduate \\ Education \\ (Kharkiv, Ukraine) \\ SI «Institute of Pediatrics, Obstetrics and \\ Gynecology NAMS of Ukraine» \\ (Kyiv, Ukraine)
}

Summary. Antenatal diagnosis of pulmonary hypoplasia and the prediction of the perinatal risk and outcome based on the analysis of fetal chest ultrasound are important in obstetric clinic and prenatal counseling. The analysis of ultrasound images and perinatal results in 24 fetuses with noncardiac chest anomalies which were revealed after 22 gestational weeks was conducted. Criteria for prognosis of perinatal risk depending on ultrasound pattern of the chest based on the literature review and own observations are presented as well as chest anomalies requiring post-natal follow-up monitoring. Given the limited possibility of retrospective crosssingle site study further prospective multicentre studies are appropriate to detect an antenatal ultrasound fetal lung changes and their association with perinatal outcome.

Keywords: antenatal sonography, fetal lungs, postnatal outcome. 